\title{
Leveraging ICT to Overcome Complementary Institutional Voids: Insights from Institutional Work by a Social Enterprise to Help Marginalized
}

\author{
Rishikesan Parthiban ${ }^{1} \cdot$ Israr Qureshi $^{2}$ [D $\cdot$ Somprakash Bandyopadhyay ${ }^{1} \cdot$ Babita Bhatt $^{2} \cdot$ Saravana Jaikumar $^{3}$ \\ Published online: 24 February 2020 \\ (C) Springer Science+Business Media, LLC, part of Springer Nature 2020
}

\begin{abstract}
There is, in general, a dearth of empirical inquiries on how institutional voids are filled through institutional work in marginalized communities. Extant studies have focussed on institutional work that addresses solitary institutional void, mostly in formal settings. In this paper, we inquire the case of a social entrepreneurial venture in India that identified two complementary institutional voids (productive ageing void of the urban elderly and rural education void of children) and attempted to simultaneously address the two voids. The issue of physical distance between the two groups was overcome by enacting an ICT platform. We also show how the institutional challenges associated with the ICT implementation led them to pursue different kinds of institutional works in their context. We then identify different theoretical dimensions of institutional works that could be used in marginalized contexts. Finally, we show how the 'complementary voids' approach has implications for both theory and practice.
\end{abstract}

Keywords Rural education void $\cdot$ Productive ageing void $\cdot$ Digital social innovation $\cdot$ Marginalized communities

\section{Introduction}

The promise and potential of information and communication technologies (ICTs) to address the social and livelihood issues of marginalized communities, ${ }^{1}$ led to a call for its inclusion in different development related initiatives (Lin et al. 2015; Tarafdar et al. 2012; Walsham 2012). In response, national governments, non-governmental organizations (NGOs), social enterprises and other developmental agencies integrated ICT channels and tools in their projects to improve the quality of service delivery in

\footnotetext{
${ }^{1}$ Marginalized communities are defined as groups of people who are confined to the lower or peripheral edge of the society due to reasons like age, mental or physical disabilities, economic conditions, access to education, or reside in isolated places or depressed regions (Haihambo 2020; Morato et al. 2016). In rural India, this marginalization extends to lower caste and women (Qureshi et al. 2018).
}

Israr Qureshi

israr.qureshi@anu.edu.au

Rishikesan Parthiban

rishikesanp15@iimcal.ac.in

Somprakash Bandyopadhyay

somprakashb@gmail.com

Babita Bhatt

babita.bhatt@anu.edu.au sectors like agriculture, crafts, health, education and banking (e.g. Jha et al. 2016). However, over the years, empirical evidence suggests that a significant percentage of the ICT based projects targeted at marginalized communities is not accessible to (e.g. Qureshi et al. 2018) or not accepted by the intended communities and hence fail to achieve the intended objectives (e.g. Avgerou 2010). Scholars have time and again reiterated how a large number of projects get dropped in the initiation phase, are abandoned during the implementation phase or turn out to be unsustainable post-implementation (Lin et al. 2015; Young 2018).
Saravana Jaikumar

saravana@iimcal.ac.in

1 Management Information Systems Group, Indian Institute of Management Calcutta, Kolkata, India

2 Research School of Management, Australian National University, Canberra, Australia

3 Marketing group, Indian Institute of Management Calcutta, Kolkata, India 
Researchers have utilized a number of theoretical lenses to understand and unearth the causes for such ICT based project failures in the marginalized communities' context (Lin et al. 2015). One of the approaches has been to consider the nature of the institutional environments within which ICT for development projects are implemented for the marginalized communities, to understand the nature of developmental efforts required in such contexts (Gregor et al. 2013; Rhodes 2009). Specifically, scholars suggest the need to better understand the elements within the institutional environments, in on order to surface the root cause of the failures of ICTs to facilitate development (Lin et al. 2015).

In this regard, researchers suggest that institutions ${ }^{2}$ within marginalized communities are often weak or are at conflict with each other (Mair et al. 2012; Mair and Marti 2009). Further, they suggest that such weakness and conflicts between institutions give rise to institutional voids ${ }^{3}$ of different kinds. Hence, institutional scholars working in these contexts characterize development as a matter of filling up of these different voids. At the same time, institutional scholars stress the need to carefully consider the nature of those institutional voids and the institutional elements that lie within, in order to gain acceptance by the beneficiaries during development initiatives. For instance, scholars point out how locally important institutional elements like historical context, social-political legacy, existing social-norms, local belief systems, path dependencies and nature of traditional authority, among others have to be taken into account while implementing interventions (Amaeshi et al. 2016; Banerjee and Jackson 2017; Bhatt et al. 2019; Mair et al. 2012) . Building on these arguments, we suggest that ICT based initiatives could fail because they don't consider such institutional elements while attempting to fill institutional voids.

In this context, institutional scholars point out how institutional work ${ }^{4}$ could be a useful theoretical lens to understand and inquire how institutional voids can be addressed. However, a review of the institutional work literature in general and institutional work in the IS domain in particular, revealed the following gaps. First, the literature suggested that there was a predominant focus on 1) empirical work in developed country contexts and 2 ) work done by powerful actors with abundant resources (Mair et al. 2012; Marti and Mair 2009). Hence, there is limited research on how actors working

\footnotetext{
$\overline{2}$ Institutions refer to both informal establishments such as stable norms, values, customs, beliefs that govern socially acceptable behaviour and formal establishments such as laws, regulations, and their supporting apparatuses (Webb et al. 2009).

${ }^{3}$ Institutional voids are defined as lack of formal institutions (or presence of weak institutions with conflicting mandate) that are required for the effective functioning of the markets (Mair et al. 2012; Palepu and Khanna 1998; Stephan et al. 2015).

${ }^{4}$ Institutional work refers to "the purposive action of individuals and organizations aimed at creating, maintaining and disrupting institutions" (Lawrence and Suddaby 2006, p. 216).
}

in developing country contexts and possessing limited resources could also engage in institutional work. In this context, scholars suggest how institutional work in these rarely explored environments can unearth new dimensions like the exploratory and developmental nature of institutional work and provide valuable extensions to the literature (Mair et al. 2012; Mair and Marti 2009).

Second, while existing literature on institutional work has considered contexts where one institutional void was addressed, to the best of our knowledge, we did not find any study that inquired contexts where more than one void was addressed. Institutional voids arise at the complex intersection of existing institutions (or lack of it) and often require very structured interventions that depend on the institutional environment and the nature of the void (Bhatt et al. 2019; Mair and Reischauer 2017; Palepu and Khanna 1998). As a result, addressing one institutional void in itself could be a set of complex activities. Hence, addressing multiple institutional voids might require even larger interacting sets of activities involving substantial efforts and perhaps need certain synergies between the voids, which may be difficult to unearth and achieve. This is perhaps the reason why such initiatives are rare and not represented in the literature.

Third, we found that extant research on institutional work in the IS domain (although sparse) focussed largely on institutional work associated with digital transformations in large organizational contexts (Guillemette et al. 2017; Troshani et al. 2018). Hence, there is a dearth of literature on ICT centred institutional work relating to marginalized communities. Hence we explore the research question -what is the nature of ICT centred institutional work carried out by actors in resource constraint environments in the presence of multiple institutional voids?

To explore and investigate the above question, we carry out an in-depth qualitative field inquiry into the case of GenLink ${ }^{5}$ that sought to simultaneously address the problem of poor quality of rural education (rural education void) and the problem of social isolation of the urban elderly (productive ageing ${ }^{6}$ void) using an ICT based platform. ${ }^{7}$ We collect data on GenLink's work over a thirty one month period that included participant observations, in-depth interviews and perusal of archival documents. Subsequently, we employ the Gioia methodology to analyse our data and uncover our themes and theoretical dimensions.

Our findings revealed how GenLink leveraged the 'complementarities' between the two voids in order to fill each void with the help of the other. Specifically, we show how GenLink

\footnotetext{
${ }^{5}$ A pseudonym for a social entrepreneurial venture in India.

${ }^{6}$ Productive or active ageing refers to ageing of the elderly with economic and social security such that they have opportunities to have a constructive relationship with the larger society (Gleason and Butler 1985; Gokhale 1998).

${ }^{7}$ GenLink provided a platform for online education to rural children wherein remote elderly teachers from urban areas taught them.
} 
used the dormant knowledge capital, often ignored by the society, of the urban elderly to provide education to the rural children from marginalized communities, who often do not get quality teachers to learn from. We also found how GenLink employed an ICT based platform to connect the two communities and overcome the issue of the physical distance between the elderly and rural children. This illustrates how GenLink made efficient use of the limited resources available at its disposal.

Further, in our findings, we elucidate GenLink's institutional work to overcome various institutional challenges by leveraging ICT to help fill the institutional voids. Rural education void presented with the institutional challenges related to the initial lack of acceptability of online education as a source of good quality teaching. Productive ageing void presented with the institutional challenges related to the elderly's productive engagement through technology. In the process, we highlight how GenLink performed different types of institutional work in an attempt to address various challenges and thereby fill the institutional voids.

In the context of rural education, we show how GenLink performed three broad categories (each of which had subcategories) of institutional work -1) legitimizing the new mode of education 2) Educating to enhance awareness and 3) Enriching the learning experience. Further, in the context of urban elderly, we show how GenLink performed two broad categories (each of which had sub-categories of institutional work) 1) Educating to (re)define norms about technology and 2) Digital On-boarding. Finally, we show how such institutional work contributes to the filling of the two institutional voids.

In this regard, we capture how GenLink's work to address rural education void helps in improving the quality of education received by the children from marginalized communities through 1) receiving passionate and quality teachers 2) increased interest in content taught 3) holistic learning and 4) accurate evaluation and tracking of progress. Also, we capture how GenLink's work to address productive ageing void contributes to the productive ageing of the elderly through 1) financial independence 2) improved sense of self-worth and 3 ) reduced social isolation.

While we highlight the salient role played by ICTs to overcome the complementary voids in our context, we make two important observations. First, we note how the ICT based activities by GenLink do not exist in a social vacuum, but lie embedded within a set of supporting social processes in the ecosystem. Second, we also emphasize that complementary voids could also be overcome without the use of ICTs in some contexts.

We leverage our study to make the following contributions to the institutional work and IS literatures. First, we introduce and conceptualize the term 'complementary voids'. We also suggest the conditions under which complementary voids may be identified. Second, we demonstrate how actors addressing multiple institutional voids simultaneously can use the complementary voids approach as one way to address those voids. We then outline the salient role played by ICT in addressing the complementary voids in our context. Third, we unearth new theoretical dimensions of ICT centred institutional work in the marginalized communities' context and show how actors working in such contexts can use it to enhance the chances of acceptance by the communities. Finally, our study also contributes to social enterprise/ entrepreneurship literature. We demonstrate how a social enterprise can leverage ICT to address social issues in resource constraint environments. For practice, we show how social enterprises with few resources can use the 'complementary voids' approach to solve social problems parsimoniously. ${ }^{8}$

The rest of the article is structured as follows. To begin with, we survey the literature on ICTs for marginalized communities, institutional voids and institutional work. Next, we elucidate the research context in which we discuss the research setting and the case organization. After this, we discuss the data collection and data analysis approach. Subsequently, we describe our findings and then discuss our contributions to the literature and practice. Finally, we acknowledge the limitations of our study and suggest directions for future work.

\section{Literature Review}

The literature review section provides the theoretical foundations for our paper and is organized into three sub-sections. First, we briefly review the role of ICTs in addressing social issues in marginalized communities. We then adopt the institutional approach to make sense of ICT based project failures. Second, we synthesize the reasons for the presence of institutional voids in marginalized communities and the need to address them to facilitate development. Finally, we engage with the institutional work literature to understand if and when these institutional voids could be overcome.

\subsection{Institutional Approach to Assessing ICT Based Development Initiatives}

Extant literature suggests ICTs could play a pivotal role in empowering marginalized communities by expanding their agency and by serving as an important enabler of opportunities (Avgerou 2003; Cruz-Jesus et al. 2017; Ganju et al. 2016). However, there is a lack of consensus on ICT driven development about: 1) the manner in which ICTs could be developed and appropriated to induce development and 2) the underlying processes by which ICT facilitate the same (Avgerou 2010).

\footnotetext{
${ }^{8}$ In our context, the elderly taught for minimal payments or even on a voluntary basis considering that children from marginalized communities cannot pay much and because this exercise helped them overcome their own social isolation.
} 
Accordingly, researchers advocated different epistemological stances on the construction and usage of digital technologies for the benefit of marginalized communities (Lin et al. 2015).

Early approaches to deploying ICT for societal benefits assumed that the cognitive elements and material structures that constitute design of and practices associated with information systems were independent of the social contexts of its use (ITU 2011; Mansell 2010). Hence, such approaches believed that technologies developed in different contexts were transferable to other societies in its near original form. As a result, this tradition underscored the importance of the 'technological artefact' and considered development of the marginalized communities as a matter of acquisition and usage of technologies through the support and training of its use (Mansell 2010). Though considerable progress was made using this approach, repeated failures of ICT based development projects led to pleas for alternative orientations (Avgerou 2003, 2010).

In response, the institutional approach surfaced as one of ways to implementing and assessing the outcomes, wherein the scholars called for greater need for social embeddedness in ICT based projects (Ashraf et al. 2009; Brooks and Alam 2013; Lin et al. 2015). According to the institutional approach, the purpose of ICT based innovations needed to arise from local conceptions of the problem of interest and be constructed considering the techno-organizational realities of the local context (Prakash and De 2015; Rahman et al. 2019; Young 2018). Further, the approach suggested that development was not a problem that required fixing but a complex sociocultural process that required an emergent understanding and evolving approaches to addresses the same ${ }^{9}$ (Jha et al. 2016; $\mathrm{Pal}$ et al. 2009). Hence, it advocated the active involvement of the target communities in the process of ideation, development and implementation and outlined that only when local actors make sense of innovation, they will accommodate it into their lives (Gregor et al. 2013; Pal 2009).

Moreover, scholars subscribing to this paradigm advocated the significance of considering local institutional elements in order to unearth the reasons for ICT based project failures (Leong et al. 2016; Lin et al. 2015; Venkatesh et al. 2016). Specifically, they argued that weak or conflicting institutions within marginalized communities gave rise to different kinds of institutional voids that had to be addressed to facilitate development (Avgerou 2003, 2010). However, extant researchers suggest that there is still a lot to know about how ICTs can help address these institutional voids in marginalized communities and the challenges associated with the same (Ravishankar 2013; Sahay and Walsham 2017). In this regard, we begin with a review of institutional voids.

\footnotetext{
${ }^{9}$ Scholars also argued that development related goals by ICTs are not caused by the artefact itself, but by the new forms of informational behaviour it facilitates (Mansell 2010).
}

\subsection{Institutional Voids: Causes and Consequences}

Institutional theory stresses the central role that institutions ${ }^{10}$ play in the development of market-based economies and in the shaping of the behaviour of actors like entrepreneurs, firms, and the society at large (Kostova et al. 2008; Stenholm et al. 2013; Wadhwani 2018). Scholars argued that when designed and implemented properly, such institutions would provide the rules of the game to facilitate the creation and functioning of ideal markets (Stephan et al. 2015; Tracey and Phillips 2011). In this context, early works by economists and strategy scholars on inquiring the reasons for the presence of undeveloped markets in developing nations, pointed to the lack of institutions or presence of weak institutions with conflicting mandate (Palepu and Khanna 1998). Such lack of formal institutions required for the effective functioning of the markets was characterized as institutional voids (Palepu and Khanna 1998; Stephan et al. 2015). For instance, lack of regulative mechanisms on the emerging notion of the gig-economy in different nations have resulted in unclear rules during disputes and compromise on worker rights (Deng et al. 2016; Mair and Reischauer 2017). Scholars agree that lack of social institutions or their presence with conflicting mandate could also give rise to institutional voids. For instance, Bhatt et al. (2019) highlight how existing social beliefs and norms relating to the unilateral role of government in solving social problems in China, lead to the creation of a non-munificent ${ }^{11}$ environment in which the society discouraged individuals from setting up social businesses (absence of social institutions to support social business).

Subsequent research on the concept, however, challenged the notion that institutional voids were spaces that were devoid/ empty of institutions. Researchers who adopted a more sociological view suggested that institutional voids could also occur when there is abundance of strong institutions. Specifically, scholars in this tradition argued that conflicts and contradictions between existing institutions could also be a source of voids. First, extant research highlights how conflicts between formal institutions with a rigid hierarchy and informal institutions embedded within local communities could give rise to institutional voids. For instance, Mair et al. (2012) demonstrated how legislation regarding property rights for women in Bangladesh were in direct conflict with the local patriarchal and patrilineal systems in rural Bangladesh and how it in turn led to lack of 'real' ownership over property for women. Second, researchers also highlighted how conflicts between different formal

\footnotetext{
$\overline{10}$ Institutions indicate both formal establishments advanced by the government, private or public entities or informal establishments such as stable beliefs, customs, norms, values and recurring behaviour patterns that are accepted and important to the society (Lawrence and Suddaby 2006).

${ }^{11}$ Non-munificence in this context refers to the lack of social resources required to support the initiation of social business (Bhatt et al. 2019).
} 
institutions could also be a source of voids. For example, past research has shown how conflicts between governments within a state that have different ideologies/motives (e.g. between a national and a regional government (Mertha 2009)) could result in policy voids that hamper developmental goals .

In this context, researchers working in this domain firmly acknowledge the need to address these different types of institutional voids in order to facilitate developmental goals. Specifically, they highlight how the different types of institutional voids can hinder market functioning, hamper market development or impede the participation of certain sections of the society in the markets (Mair and Marti 2009). Hence, researchers in the development studies domain suggest how the filling up of such voids could be a means or end to achieving development (Mair and Marti 2009). In this regard, we now consider institutional work as one approach to address the institutional voids in the context of marginalized communities.

\subsection{Institutional Work in Marginalized Communities}

The concept of institutional work emerged as a response to the call for considering the recursive relationship between actors and institutions, by shifting the focus of studies to inquiries on how actors' actions impacted institutions ${ }^{12}$ (Lawrence et al. 2013; Lawrence et al. 2009; Lawrence and Suddaby 2006; Qureshi et al. 2016). Its fundamental premise hinged on three key elements: 1) it pivoted on the reflexivity and skill of actor(s), 2) it was based on the understanding that institutions were constituted based on the conscious/intentional actions of actor(s) and 3) it acknowledged that actor(s) who attempted to create/maintain or disrupt the institutional order are themselves embedded within the existing institutional rules, norms and beliefs (Lawrence et al. 2009; Lawrence and Suddaby 2006). In this context, institutional work was defined as the deliberate and purposive actions of individual or organizational actors that aimed to disrupt, maintain or create institutions (Lawrence and Suddaby 2006).

A significant aspect of the concept of institutional work is its balance between agency and structure. On the one end, the proponents of institutional work believe that agents are not mute spectators and zombies to structure around them; however, on the other end they also do not believe in the dominant heroic perspective of agency that characterizes most empirical accounts on institutional entrepreneurship ${ }^{13}$ (Lawrence et al. 2009; Lawrence and Suddaby 2006; Marti and Mair 2009).

\footnotetext{
12 Institutional approaches to the study of organizational/societal actors traditionally focussed on the relationship between the actors and the fields in which they operated by providing accounts on how institutions governed actors' actions (Lawrence et al. 2009; Lawrence and Suddaby 2006).

${ }^{13}$ Institutional entrepreneurship is defined as a set of activities by actors who question the existing institutional norms/beliefs and go on to create new or disrupt existing institutions (Wang and Swanson 2007).
}

Consequently, its proponents stressed the importance of encompassing a broader range of actors, activities and contexts within which institutional work could occur (Lawrence et al. 2011). However, surprisingly, a review of the literature on institutional work revealed that most research efforts were still focussed on work done in developed countries, and on work by actors who had plenty of resources at their disposal (Mair et al. 2012; Marti and Mair 2009; Venkataraman et al. 2016). In this context, Marti and Mair (2009) introduced how inquiries on institutional work in atypical contexts (e.g. in marginalized communities) are significant for both theoretical and practical reasons and appealed for more research in such contexts to help capture the different facets of institutional work more comprehensively, besides helping to advance approaches to solve social problems in such communities (Marti and Mair 2009). We conceptualize the theoretical foundations for our paper based on this growing literature which is still in its infancy (Hamann and Bertels 2018; Lawrence et al. 2011; Zietsma and Lawrence 2010).

First, the scholars suggest how the nature of institutional work by social entrepreneurs working in resource-constrained environments could be exploratory (involving small, gradual and reversible steps) as opposed to the aggressive jolts enacted by powerful actors (Marti and Mair 2009; Venkataraman et al. 2016). Empirical work in this regard, demonstrates how constant probing for weaknesses and exploitation of small gains reduces counter-mobilization from those seeking status quo (Mair et al. 2012). Further, scholarly work has explored the notion of institutional bricolage in this context and highlighted how marginal actors working in resource-constrained environments incrementally deploy and innovatively recombine existing resources (Domenico et al. 2010; Hota et al. 2019).

Second, researchers have mentioned how work in marginalized communities could be related to enhancing institutions wherein actors attempt to complement and broaden the scope of extant institutions (Marti and Mair 2009). In this type of work, the proponents work towards addressing the barriers towards accessing extant institutions and hence attempt to make them more inclusive (Mair et al. 2012; Mair and Marti 2009). For instance, the microfinance movement in many of the developing nations like Bangladesh can be seen as an attempt to make banking more accessible to the poor and illiterate (Chemin 2008).

Third, extant research in this domain shows how much efforts by actors are dedicated towards transforming extant norms, beliefs and traditions (Mair and Marti 2009), and suggests that unlike rules, norms and beliefs are a matter of faith to local communities and hence are deeply entrenched within the practices of the communities (Bhatt et al. 2019). As a result, it is argued that engagement with influential people in the communities and their trust is needed to push for any societal changes (Marti and Mair 2009; Venkataraman et al. 2016). 
Fourth, scholars suggest the significance of the creation of provisional institutions that serve a certain purpose for a specific period of time (Lawrence et al. 2002; Marti and Mair 2009). Here, researchers suggest how such institutions may be dissolved once the local communities are empowered to act without them (Kistruck et al. 2013). For example, the literature suggests how social intermediaries may create provisional institutions to facilitate transactions for BoP producers and consumers and disengage them once the beneficiaries have acquired sufficient capabilities to act on their own (Cui et al. 2017; Jha et al. 2016; Kistruck et al. 2013).

Finally, we know from extant research how institutional voids that arise in such communities owing to different conflicting and contradicting logics require multi-faceted strategies that can navigate through the different logics (Mair et al. 2012). For instance, researchers highlight how NGOs in Bangladesh borrowed elements from religious and cultural domains to promote health and hygiene practices (Mair and Marti 2009). However, a review of the literature revealed that no academic insights exist to understand how actors navigate through the different challenges when they address more than one institutional void at the same time. Specifically, scholars suggest how working to address a unilateral institutional void in resource-constrained environments is a complex activity that may require actors to combine and make do with available resources at their disposal (Domenico et al. 2010; Hota et al. 2019; Marti and Mair 2009). Consequently, we argue that working around multiple institutional voids would further be complicated by the need to tackle multiple interacting institutional challenges simultaneously and would thus require entrenched sense making, multidisciplinary and innovative approaches (Dorado and Ventresca 2013; Osland and Bird 2000). This may be the reason why empirical work on multiple institutional voids is not represented in the literature.

In the IS domain, the research on how digital technologies can play a key role in addressing different institutional voids is in infancy (McGrath 2016). The limited research that take into account social context has highlighted how digital social innovations that are not congruous with extant norms, beliefs and practices may be met with resistance from the target communities (Binz et al. 2015; Gregor et al. 2013). Hence, researchers have suggested how obtaining legitimacy for such innovations could require institutional work, although not using this label per se, that creates an alignment between the technology and the institutional context in which such technologies are deployed (Binz et al. 2015; Henriksen et al. 2014). However, we argue that studies till now have focussed largely on the challenges associated with technology implementations and digital transformations in large organizational contexts (Hinings et al. 2018; Troshani et al. 2018). For instance, Guillemette et al. (2017) discuss how information technology function types and organizational objectives mutually evolved and shaped each other through institutional work in a large health care organization. Consequently, there is paucity of work when it comes to understanding the nature of ICT centred institutional work to address institutional voids in the context of marginalized communities. Hence, to address these gaps in the institutional work literature in general and institutional work in the IS domain in particular, we study how ICTs are used to address more than one institutional void in marginalized communities, using the theoretical lens of institutional work.

\section{Research Context and Method}

In this section, we first provide a brief overview of the two institutional voids: 1) regarding the quality of education in the rural Indian context (rural education void); and 2) the lack of productive ageing opportunities for the elderly in the urban Indian context (productive ageing void). Next, we provide an outline of the case organization that attempted to simultaneously address these two problems. Finally, we describe the data collection and data analysis approach that was adopted in this research.

\subsection{Research Setting}

\subsubsection{Issues with the Rural Education System in India}

India is a nation where a majority of the population still lives in the villages (Sharma 2018). Hence, recognizing the need to provide quality education to the rural population, the government initiated Sarva Shiksha Abhiyan, ${ }^{14}$ Mid-Day Meal Scheme, ${ }^{15}$ and other programs (Kainth 2006). However, despite massive investments by the government and a large number of people involved in this regard, success is still limited (Agrawal 2014). There are a number of factors that impede the growth of quality education in rural India as outlined below.

First, one of the most important factors that affect the quality of rural education is the lack of availability of good quality teachers (Afridi 2011). Teachers in both government and private schools in rural India often lack the academic qualification, training or motivation required to impart good quality education (Agrawal 2014). To make matters worse, the government teachers are burdened with many official assignments like collecting census, conducting poverty surveys, and promoting family planning programmes etc., resulting in the absenteeism of the teachers (Dreze and Kingdon 2001). Such

\footnotetext{
${ }^{14}$ Sarva Shiksha Abhiyan or Education for All Movement is a program by the government of India that makes free and compulsory education for children between the ages of 6-14 as a fundamental right (Kainth 2006).

${ }^{15}$ Mid-Day Meal Scheme is a program by the Government of India that provides free lunch to children on working days as a means to improve the nutritional standing of children (Kainth 2006).
} 
factors discourage students from being regular to school and make them disinterested in learning (Agrawal 2014).

Second, poor transportation infrastructure forces many students to walk several kilometres to reach school and thus demotivates them to attend schools regularly (Siddhu 2011). Third, because rural kids often hail from poor backgrounds, they are expected to contribute to family income. This makes them to either drop-out or become irregular to school, thereby, causing them to miss out on learning opportunities (Choudhury 2006). Fourth, in the absence of any educational support at home, rural students need extra time and much more attention to cope up with their academics. However, underqualified, expensive and abusive local tuition ${ }^{16}$ teachers deter them from getting such opportunities (Afridi 2011). Fifth, in the specific case of female children, absence of good quality washrooms in schools acts as an important hindrance for them to drop out of schools at an early age (Leach and Sitaram 2007). Finally, the prevalence of discrimination on the basis of caste (Qureshi et al. 2018), gender (Maurer and Qureshi 2019), and class (Hota et al. 2019) has also remained a complex problem in rural schools that further contributes to the drop put rates (Borooah and Iyer 2005). In this context, we characterize such problems with the quality of education in rural India due to market, state and socio-cultural factors as an institutional void (rural education void).

\subsubsection{Problems and Perceptions of the Elderly in India}

Historically, the elderly in India were revered for their wisdom and knowledge (Jeste and Vahia 2008). However, with the fragmentation of the joint family system and consequent nuclearization of families, the elderly were forced to be detached from the family (Bandyopadhyay et al. 2015). Often, they are stereotyped as being unproductive and incompetent. As a result, they are considered as a burden to the family and are forced to live alone in their own homes or old-age homes (Dionigi 2015). Such practices create problems for the elderly like lack of safety, lack of emotional support, financial insecurity, social isolation, among other things (Ingle and Nath 2008).

The negative stereotype is reiterated by the media that prefers to celebrate the young body and typecast the old as frail and undesirable (Dionigi 2015). The Indian cultural texts also resonated similar sentiments by stratifying the role of people in society based on age (Tiwari and Pandey 2013). Elderly are supposed to live a life of asceticism - a state of mind that is marked by renunciation of material gains and worldly desires and reflected in behaviour as disinterest and detachment from material possessions. Most of the elder persons give up worldly pleasures, materialistic possessions and attachment to the

\footnotetext{
${ }^{16}$ A tuition centre is typically a private institution that serves to supplement the education received in school. Tuition centres usually help students to tackle exams and advocate rote learning.
}

family. In contemporary times however, such dissociation from material life is construed as non-involvement in productive markets and hence considered as a liability. Such biases create a feeling of weakness and depression among the elderly since they are embedded in that environment (Ingle and Nath 2008). We characterize such social isolation of the elderly and the lack of opportunities for productive ageing due to social norms, beliefs and stereotyping as an institutional void (productive ageing void). In this context, we discuss GenLink's work to address the two institutional voids.

\subsection{Digital Social Innovation}

The study was set at GenLink, a social-entrepreneurial venture that was headquartered in the city of Kolkata in India. The founders of GenLink came up with the idea of bridging the two marginalized communities, namely the elderly and the rural children using an ICT platform and thereby leverage it to solve some of the problems of both the communities simultaneously. Specifically, they wished to utilize the ignored wisdom of the past generation (elderly as the source of knowledge) to educate the future generations (rural children as the sink of the knowledge).

However, the founders realized that such an aspiration would entail the complex task of matching the requirements of two completely contrasting worlds: - 1) the world of the disadvantaged rural children who required quality, regular, timely and interesting educational inputs that would help fill the gaps in their existing systems. 2) The world of the elderly who required flexibility in terms of work schedules, working hours and workplace due to personal commitments and health-related problems due to ageing.

To achieve this, the founders enacted a system that had five basic agents 1) senior citizens as the teachers 2) cyber-citizens' skill capital 3) Non-Governmental Organizations (NGOs)/Village Level Entrepreneurs (VLEs) as owners of the internet schools in the villages 4) cyber world's knowledge capital and 5) rural children as the recipient of the knowledge. The system worked as follows. To begin with, the firm engaged volunteers and freelance developers (cyber citizens) to create standardized digital content in local language. The cyber citizens were encouraged to utilize the multimedia cyber content from recognized sources available on the web as reference during the content development process.

Next, the elderly teachers utilized these materials to deliver classes online to the rural children. In the rural areas, VLEs/ NGOs created the classroom infrastructure required for the delivery of classes and mobilized students. GenLink created different checks and balances to ensure that the classes occurred regularly and seamlessly. First, the firm employed field coordinators who collected and reported the issues faced by the internet schools, facilitated the cross-checking of student attendance, teacher feedback, among other things and deployed 
surveys to conduct impact analysis. Next, the field coordinators in turn reported to a field manager who visited the schools periodically to perform audits. On the teacher's front, GenLink had a pool of elderly citizens who were qualified to ensure that teachers who were absent could be substituted. The classes were also monitored online for quality check on a periodic basis from the headquarters.

In the GenLink system, the rural children paid a highly subsidized fee to the franchise owners who relied on numbers to achieve sustenance. GenLink charged a small percentage of the profits from the internet school owners to cover its field operations. To further cover the expenses of other operations, GenLink operated in a cross-subsidy model in which it also catered to the requirements of the urban students. ${ }^{17}$ The urban students took one-to-one personal online classes and were charged a premium.

\subsection{Data Gathering}

The data we utilized for this research study came from multiple rounds of data gathering from a variety of sources.

Participant Observations: We performed ethnographic field observations during the period June 2016-December 2018. One of the authors spent time at the GenLink's headquarters during the pre-formative moments, formative moments and the implementation phase and conducted participant observations of most of the important events. One of the authors also conducted field visits to the villages where the internet schools were implemented and observed the classes in situ. One of the authors also remotely observed different online classes where the elderly taught the rural children.

Semi-structured interviews: We conducted semi-structured interviews with key stakeholders in GenLink's ecosystem. Interview participants included the three founder-directors, project managers, project team members, internet school owners, elderly teachers and students. Interviews were audiotaped with the permission of the participants.

Archival documents: We also utilized archival data like annual reports, impact analysis reports, pamphlets, videos, pictures, (conditional access to) internal documents, minutes of the meetings, among other things for our analysis. We were also given access to view the GenLink's information system that included different front-end and backend modules. Appendix Table 3 summarizes the data that was gathered for the analysis.

\subsection{Data Analysis Approach}

To begin with, we compiled and organized the different forms of data gathered like interview transcripts, pictures, videos,

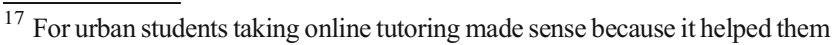
save commute time to and fro to offline tutoring centres.
}

field notes and other archived data (Eisenhardt 1989; Yin 2003). Overall, we followed the established approach suggested by Gioia et al. (2013) for our data analysis. The data management and coding was done manually using standard word processing and spreadsheet software. Our data analysis followed an iterative approach as suggested by Gioia et al. (2013) and involved two steps as discussed below.

\subsection{Step1: First Order Analysis}

In the first order analysis, we went through the transcripts and other archived documents to identify the different informant terms and marked them as different categories (Gioia et al. 2013). Subsequently, similarities and differences between the different informant categories were identified and distilled to a manageable number of first order codes (Gioia et al. 2013). Care was taken to faithfully represent the informant terms while labelling the first order codes. For instance, we found many instances in our data where the interviewees talked about the use of teachers who were physically present in the classroom and assisted the virtual elderly teacher by monitoring the students, collecting attendance records, facilitating smooth conduct of exams, looking into technical issues, among other things. This was captured as the first order code 'Deployment of the Para teacher'. The entire process of first-order analysis was iterative in which we looked at the data for repeated presence or absence of categories (Gioia et al. 2013). We then read and reread our data to recode the labels based on our emergent and evolving understanding. Thus, our first order codes involved the refinement of our raw data into our initial interpretation. Appendix Table 3 and 4 shows the representative quotes for each first order code.

\subsection{Step2: Second Order Themes and Aggregate Dimensions}

The second order analysis involved the search for a deeper structure into the array of first order codes (Gioia et al. 2013). It involved the simultaneous thinking at informant level and at the abstract level of second order themes. This stage involved subsequent interviews to make focussed sense of the emergent second order themes. For instance, the different first order codes that related to the extension of traditional school features to internet school were combined into 'Creating a blended learning environment'. Once a workable set of second order themes were constructed, we then embarked onto combining the related second-order themes into aggregate dimensions (Gioia et al. 2013). This stage involved moving back and forth between the themes and the literature and consequent identification of theoretical 
categories that did not have adequate referents in the extant literature (Gioia et al. 2013). For example, we identified Legitimizing the new mode of education as a type of institutional work carried out by GenLink to gain acceptance from the rural people. The data structure that we developed through this entire process can be found in Tables 2 and 3.

\section{Findings}

\subsection{Using ICTs to Leverage the Complementarities between the Two Voids}

Our findings revealed how the founders of GenLink identified the 'complementarities' between the problems faced by the two marginalized sections - the senior citizens and the rural children. In this regard, the founders recognized how the senior citizens, despite possessing a lifetime of experience and knowledge, were ignored by the society post-retirement and hence did not get the opportunities to do any productive activities. The founders also discerned the problems associated with the quality of rural education and the unsatisfactory role played by the tuition ${ }^{18}$ teachers to fill the gaps in the education system. Many respondents expressed these concerns:

When I am in [major Indian city], my day starts and ends with almost no activity. ... Sometimes, I think about starting my own [small] business just to engage myself. ...It's tough to be idle throughout the day. ... But since I was a teacher before, it's not in my nature to do such kind of activities. ...My children are very busy and hence find it difficult to support my ideas. (Senior Citizen 1, Major City India)

If you look at the schools here, the teachers are not good enough. ...Both the government and private schools here lack the necessary facilities to provide good education. Even the English teachers will not be able to converse in English properly. ...Usually, the existing teachers only provide tuitions. So they don't really solve the problem. ... One of my kids studied here. ....Even though he was ok with the subjects, he struggled in college and did not get employment. ...Ultimately, real knowledge is received only by the kids in the cities. (Parent 1, Rural India)

One of the founders highlighted how both the problems were complementary to each other:

\footnotetext{
${ }^{18}$ A tuition centre is typically a private institution that serves to supplement the education received in school. Tuition centres usually help students to tackle exams and advocate rote learning.
}

After retirement, many elderly live an isolated life both socially and economically. Although, quite of few of them have the capability and interest, they don't get the scope to enter any mainstream activity. ...In the rural context, on the other hand, there is a dearth of good quality teachers...We thought that it would a nice idea to implement a video conferencing platform in which elderly teachers from [major Indian city] would teach them. (Founder Director 1, GenLink)

In this context, ICT became central to their mission of connecting the two marginalized communities (and solving both their problems together) owing to the spatial separation between the two sections and the preference of the elderly to stay at their own homes and work at their own times. GenLink thus came up with a technology platform to provide online education to the rural underprivileged children:

A NGO in [a small village] complained that there was dearth of teachers since the NGO was working deep in a remote village.... Volunteers from [major Indian city] used go there, stay there for two weeks, teach some subjects and then come back. So retaining those volunteers was difficult. The founder (of the NGO) came to me asking for teachers who can go there and spend some time. ...We started the pilot with him using skype where our elderly teachers taught the children....We then went on to build our platform. (Founder Director 2, GenLink)

Our analysis also revealed that there was a deeper reason for the complementarity between the two communities than just the knowledge source-sink connection. The elderly teachers acknowledged that they were in the phase of renunciation. However, the elderly teachers contested the popular perception that people in this phase should detach from all aspects of socio-material life. Specifically, the elderly stressed that detachment to them meant relinquishment from the endless want for materiality in life, but at the same time meant contribution to societal benefits. In this regard, the teachers mentioned how their services (as volunteers or for a very basic honorarium) to the underprivileged children resonated well with this philosophy:

I derive my philosophy on [renunciation] from the teachings of Ramakrishna Paramahamsa. ${ }^{19}$ If you touch the scales of a fish, it will simply not be wet. Its scales, much like the lotus, don't attach itself to water. [Renunciation] to me is like that. You still swim in the water without attaching yourself to it. Many people think [renunciation] is simply about jumping out of the

\footnotetext{
${ }^{19}$ Ramakrishna Paramahamsa was an Indian saint who lived in nineteenth century Bengal.
} 
water. To me, it's about staying in the water, contributing to the ecosystem and yet detaching from its material aspects. ...I don't charge a single penny for my services to the rural children. Yet, it is the one thing that makes me happy. (Elderly Teacher1, GenLink)

The children, on the other hand, got to learn from the elderly teachers who imparted not only academic knowledge but also stories, poems among other things. Our data corroborated from different sources revealed how the children preferred the elderly teachers over the local tuition teachers who were uninterested in teaching or underqualified:

The elderly teachers are in great demand here because they are affectionate and teach in such a nice way. The children love them. ... They (elderly teachers) try to teach through storytelling and the students like it a lot. (Internet School Owner1, GenLink)

However, GenLink's aspiration to use ICTs to fill both the institutional voids did not occur without challenges. Specifically, the founders faced the challenge of lack of acceptability of online education in rural India and the challenge of productive engagement of the elderly through technology. We discuss how GenLink addressed the two institutional challenges by embedding their work within the larger institutional structures and elements present in both the marginalized communities.

\subsection{Addressing the Institutional Challenges through Institutional Work}

\subsubsection{Adressing Rural Parents' Lack of Acceptability of Online Education}

To address the problem of acceptability of online education, GenLink did three types of institutional work -1) legitimizing the new mode of education 2) Educating to enhance awareness and 3) Enriching the learning experience (see Table 1). We discuss each of these efforts in detail below.

Legitimizing the New Mode of Education Online education was a new phenomenon for the parents of the rural children, who preferred the physical presence of a teacher even if he/she is underqualified. Further, the tuition teachers, being the only learned individuals in the villages, were venerated for their knowledge and were hence influential:

In rural areas, the tuition teacher usually assembles children from different grades and makes them do homework, read on their own and so on. Parents prefer them even if they are underqualified ... because it's a physical teacher. ...In our case, they find it (online education)
Table 1 Data Structure on the Institutional Work to address the challenge of lack of acceptability of online education in rural India

\begin{tabular}{|c|c|c|}
\hline First Order Codes & $\begin{array}{l}\text { Second Order } \\
\text { Themes }\end{array}$ & $\begin{array}{l}\text { Aggregate } \\
\text { dimensions }\end{array}$ \\
\hline $\begin{array}{l}\text { Teaming up with local NGOs, } \\
\text { govt. schools, self-help } \\
\text { groups, local clubs }\end{array}$ & \multirow[t]{2}{*}{$\begin{array}{l}\text { Collaborating with } \\
\text { local arrangements }\end{array}$} & \multirow[t]{7}{*}{$\begin{array}{l}\text { Legitimizing the } \\
\text { new mode of } \\
\text { education }\end{array}$} \\
\hline $\begin{array}{l}\text { Wherever possible, preferred } \\
\text { local tuition teachers, } \\
\text { educated people and } \\
\text { students as partners }\end{array}$ & & \\
\hline Deployment of Para-teacher & \multirow{3}{*}{$\begin{array}{l}\text { Creating a blended } \\
\text { learning } \\
\text { environment }\end{array}$} & \\
\hline $\begin{array}{l}\text { Periodic visit of online } \\
\text { teachers to the internet } \\
\text { school in person to give } \\
\text { feeling of traditional } \\
\text { classroom }\end{array}$ & & \\
\hline $\begin{array}{l}\text { Devices to help teachers hear } \\
\text { students and vice versa, } \\
\text { projection of teacher's } \\
\text { screen in the internet school }\end{array}$ & & \\
\hline $\begin{array}{l}\text { Use local influencers like } \\
\text { panchayat head, educated } \\
\text { people, and respected } \\
\text { elders }\end{array}$ & \multirow[t]{2}{*}{$\begin{array}{l}\text { Engaging through } \\
\text { local influencers }\end{array}$} & \\
\hline $\begin{array}{l}\text { Local influencers talk about } \\
\text { online education as a matter } \\
\text { of status symbol for the } \\
\text { village }\end{array}$ & & \\
\hline $\begin{array}{l}\text { Awareness creation through } \\
\text { advertisement in panchayat } \\
\text { offices and other places of } \\
\text { gathering }\end{array}$ & \multirow[t]{2}{*}{$\begin{array}{l}\text { Promoting in locally } \\
\text { relevant methods }\end{array}$} & \multirow[t]{5}{*}{$\begin{array}{l}\text { Educating to } \\
\text { enhance } \\
\text { awareness }\end{array}$} \\
\hline $\begin{array}{l}\text { Awareness creation through } \\
\text { advertisement via mobile } \\
\text { speakers in villages }\end{array}$ & & \\
\hline $\begin{array}{l}\text { Parent involvement in the } \\
\text { classes through in class } \\
\text { visits, parent teaching } \\
\text { meeting }\end{array}$ & \multirow[t]{3}{*}{$\begin{array}{l}\text { Enhancing } \\
\text { engagement with } \\
\text { key stakeholders }\end{array}$} & \\
\hline $\begin{array}{l}\text { Screening of educational } \\
\text { movies and arranging } \\
\text { educational trips to engage } \\
\text { parents and students }\end{array}$ & & \\
\hline $\begin{array}{l}\text { Free demo sessions to attract } \\
\text { students }\end{array}$ & & \\
\hline $\begin{array}{l}\text { Multi-media content to make } \\
\text { learning interesting }\end{array}$ & \multirow{4}{*}{$\begin{array}{l}\text { Making the learning } \\
\text { process more } \\
\text { engaging }\end{array}$} & \multirow{6}{*}{$\begin{array}{l}\text { Enriching the } \\
\text { learning } \\
\text { experience }\end{array}$} \\
\hline $\begin{array}{l}\text { Inclusion of poems, } \\
\text { storytelling by the elderly } \\
\text { teachers }\end{array}$ & & \\
\hline $\begin{array}{l}\text { Personal counselling for } \\
\text { students on a periodic basis }\end{array}$ & & \\
\hline $\begin{array}{l}\text { Personal post class sessions } \\
\text { for doubt clarification }\end{array}$ & & \\
\hline $\begin{array}{l}\text { Enactment of robust online } \\
\text { evaluation system }\end{array}$ & \multirow{2}{*}{$\begin{array}{l}\text { Standardizing } \\
\text { templates for } \\
\text { monitoring and } \\
\text { progress }\end{array}$} & \\
\hline $\begin{array}{l}\text { Analytics system to track } \\
\text { progress of each child }\end{array}$ & & \\
\hline
\end{tabular}


difficult to understand because they can't feel the physical presence of the teacher. (Manager2, GenLink)

In this context, GenLink adopted different strategies like collaborating with local arrangements, creating a blended learning environment and engaging through local influencers in order to gain legitimacy for their new mode of education. Collaborating with local arrangements involved teaming up with local NGOs, clubs, Self-Help-Groups (SHGs), educated youngsters, among others in order to gain the trust of the people. Such local arrangements also provided the infrastructure required to set-up the internet schools. Moreover, GenLink also attempted to give priority to the existing tuition teachers (as owners of the internet schools) wherever possible, in order to gain credibility and reduce counter-mobilization from these tuition teachers:

We tie up with NGOs and educated youngsters to set up the internet schools. ... They own the internet schools and manage everything, with some support from us. ...If they (tuition teachers) cooperate, we prefer to tie up with the existing tuition teachers because they know the ground situation better. ..Training them is also very easy. One thing we have now started doing is promoting women SHGs as owners of the internet schools, since women understand the value of education more and hence can mobilize the students better (Founder Director 1, GenLink)

Creating a blended learning environment concerned the enactment of elements/features within the internet school that closely resembled those in the traditional schools. First, GenLink ensured that every internet school had a para-teacher ${ }^{20}$ who was physically present to monitor the students, clarify doubts, conduct evaluations, and take attendance, among other things. Second, features like microphone, blackboard and speakers were set up in the internet school, while the elderly teachers were allowed to share their screens, write out on the shared screen and project pictures and videos. Third, the elderly teachers also periodically visited the internet schools over the weekends and physically took the classes. The focal objective of these activities was to provide familiarity to both the parents and students, given that online education was new to them:

They (para-teacher) monitor the students while the classes are going on. ...They have to coordinate because students maybe shouting, maybe moving off, or can't understand what is going on, or can't listen and so on. ...We also use speakers and microphones to help the

\footnotetext{
${ }^{20}$ Para teacher refers to a teacher who is physically present in the internet school in the villages to augment the virtual teacher who teaches from the city. The para teachers help in the smooth conduct of the classes.
}

students hear the teachers and vice versa....The teacher sometimes goes there (rural internet school) for one week and teaches different batches in the morning, afternoon, evening, and even night, continuously. ... These things are helping us gain the trust of the people in the community (Manager2, GenLink)

Engaging through local influencers related to the convincing of the Panchayat head, educated people and other respected elders and the use of them to mobilize students for the internet school in the villages. GenLink acknowledged that they would be seen as outsiders in the marginalized communities in which they sought to intervene. Hence, GenLink recognized the importance of connecting with the people through these influencers in order to gain their trust. The influencers in turn talked to the people in the village about the benefits for the children, the prestige that online education would bring to their village, among other things:

We talk to the Panchayat (village council) leaders and other respected people and they convince the parents because they know the community, they know the language out there, they know the mentality of that people or how to convince them, they know how to get something done. ... These people also talk about how this 'online thing' (internet school) will bring recognition to their village. (Manager2, GenLink)

Educating to Enhance Awareness Addressing the lack of awareness and acceptability of online education also required educating the parents about the nature of education GenLink had to offer and about the possible benefits it could bring to its children. In this regard, GenLink did two kinds of institutional work: 1) promoting in locally relevant methods and 2) enhancing engagement with key stakeholders. Promoting in locally relevant methods involved creating awareness about GenLink' education model, the kind of teachers who teach on its platform, the nature of its content and the importance of quality education in general. GenLink's field coordinators put posters and hoardings in strategic locations like the Panchayat office, and other places of gathering. Further, the GenLink also adopted the use of mobile mic sets for promotion:

The internet school owner takes the permission of the Panchayat leader and puts up hoardings in the Panchayat office and other places where adda ${ }^{21}$ happens. Posters and pamphlets are also distributed to schools and in the mela. ${ }^{22}$ We also advertise in local

\footnotetext{
${ }^{21}$ Refers to a place where people gather for conversations.

${ }^{22}$ It is fair/market place that exists for a specific period of time.
} 
newspapers. ... Besides all this, we deploy roaming mic sets that make announcements about our events. (Founder Director 1, GenLink)

Enhancing engagement with key stakeholders involved building rapport with the parents and the extended community. GenLink engaged with parents and their children by organizing periodic education cum fun trips to nearby destinations. Further, the GenLink's field coordinators with the help of the internet school owners also used the internet school infrastructure to screen educational movies where both parents and their wards were invited. Besides this, GenLink also arranged for periodic parent-teacher meeting sessions wherein they discussed the progress of each child. Parents were also invited to observe the classes that were taken for their children in situ. Finally, free demo sessions were organized for prospective parents and their wards, wherein they were invited to attend the classes and clarify any doubts they may have about online education and its efficacy:

Whenever, I go, I make it a point to meet each and every parent and talk to them. ... We allow parents to sit with the children during movies and also allow them to view the classes as long as they don't talk. ...We also organize short picnics and eating fests where the parents can join. ... No matter how interested the students are, it's the parents who will ultimately make the decisions and do the payment. ... So it's important to engage them. (Manager2, GenLink)

Enriching the Learning Experience The founders recognized that one way to gain traction among the rural population would be to highlight the unique elements that GenLink would provide and use those elements, to visibly demonstrate the quality of education that they sought to provide. In this regard, the founders did three types of work: 1) making the learning process more engaging, 2) providing personal attention and 3) standardizing templates for monitoring and progress. Making the learning process more engaging for the children involved the use of multimedia content like videos, pictures and animations to attract the attention of the students inside the classroom. Since, these elements were rare in the rural educational system in India; it helped retain the attention of the students during sessions. Besides this the elderly teachers also recited poems, told stories, among other things in order to make the learning experience more holistic:

The content shown by the teachers create interest for the students and their parents. The videos, pictures and other things help keep the students attentive. Whenever the para-teacher feels that the students are getting distracted, she requests the teacher to play some video or tell some story to bring them back to the class. (Internet school Owner 1, GenLink)

Providing personal attention concerned the individual care provided to each student within the internet school. The founders created provisions in which students could clear their doubts on an individual basis after the end of each session. Further, dedicated slots were reserved for counselling wherein students booked appointments with the teachers and received guidance on problems relating to their academic and personal life:

I have seen many students stay back after the class to clear their doubts. The elderly teachers are cooperative that way. ...We also keep slots reserved on Sunday for counselling (Manager2, GenLink)

Standardizing templates for monitoring and progress related to the enactment of a robust system to monitor and track the progress of every child. Given that the teachers and students were spatially separated, the founders created a centralized app that archived all the documents related to testing and evaluation. Elderly teachers provided their question papers in digital form, while answer scripts of children were sent to the elderly for evaluation again in digital form (using photographs). Moreover, all evaluations of students including attendance, classroom participation and marks secured in exams were fed into GenLink's analytics engine that helped generate insights about the progress of the child:

We use two applications, one is the coordinator app and one is the teacher app. The teachers and the coordinators enter all the data like attendance, exam marks and observations in this app. ...In the back end, we use this data to do some analytics and get insights about the children. (Founder Director 2, GenLink)

\subsubsection{Addressing the Challenge of Productive Engagement of Elderly through Technology}

To address the problem of elderly's lack of familiarity with technology, GenLink performed two kinds of institutional work: 1) educating to (re)define norms about technology and 2) digital on-boarding (see Table 2). We discuss each of these efforts in detail below.

Educating to (Re)Define Norms about Technology Most of the senior citizens who worked with GenLink completed their work life with little or no exposure to ICTs in general and computers in particular. As a result, they had a general lack of awareness about technology and some even feared it. GenLink thus undertook two kinds of institutional work: 1) 
Table 2 Data Structure on Institutional Work to address the challenge of elderly's productive engagement through technology

\begin{tabular}{lll}
\hline First Order Codes & $\begin{array}{l}\text { Second Order } \\
\text { Themes }\end{array}$ & $\begin{array}{c}\text { Aggregate } \\
\text { dimension }\end{array}$ \\
\hline $\begin{array}{c}\text { Sensitizing on how } \\
\text { technology can help share } \\
\text { their knowledge to the } \\
\text { larger mass }\end{array}$ & $\begin{array}{c}\text { Creating awareness } \\
\text { about the benefits } \\
\text { of technology }\end{array}$ & $\begin{array}{c}\text { Educating to } \\
\text { (re)define } \\
\text { norms about } \\
\text { technology }\end{array}$ \\
$\begin{array}{l}\text { Explaining how technology } \\
\text { would provide flexibility }\end{array}$ & \\
in workplace, working & & \\
hours and work schedules & & \\
Addressing fear of & Breaking the & \\
technology through & preconceived & \\
handholding & notions about & \\
Addressing mental blockage & technology & \\
regarding technology use & & \\
by showing role models & & \\
through videos & & \\
Periodic group training & Initiating digital & Digital \\
sessions for the elderly & literacy & On-boarding \\
teachers & & \\
Offline and online personal & & \\
coaching to use audio & & \\
aids, projecting screen & & \\
while teaching online & & \\
Enhancing the & & \\
user-friendliness of the & Enhancing ease of & \\
GenLink interface & & \\
Providing detailed manuals & & \\
and videos to simplify & & \\
usage of the portal & & \\
\hline
\end{tabular}

creating awareness about the benefits of technology and 2) breaking the preconceived notions about technology. Creating awareness about the benefits of technology involved letting the elderly know how technology can help share their knowledge to the broader society, especially the marginalized sections. Further, the founders also talked about other benefits like getting to work out of their own homes, at their own times and schedules:

Although the elderly had some idea about computers, they had never used it in their life. Our team of interns showed videos on how technology can help them share their knowledge just by working out of home. (Founder Director 2, GenLink)

Breaking the preconceived notions about technology involved the addressing of different kinds of fear about technology through personal training and handholding sessions. Further, the elderly teachers' hesitancy and mental blockage regarding the use of technology were addressed by showing the success stories of others who managed to learn and use technology for their benefits and for the benefits of others:
When we began, some of the elderly were very scared of the computer. ... They thought that they would break the keyboard or damage the screen. ...Some even felt that the internet would swindle away all their money....we hired interns who used to sit with them and motivate them to learn computers through videos. (Founder Director 2, GenLink)

Digital on-Boarding Given that the elderly lacked exposure to the use of technology, the founders did two kinds of institutional work to enable their onboarding to the digital world: 1 ) initiating digital literacy and 2) enhancing ease of technology use. Initiating digital literacy involved a series of group and personal training sessions on different aspects of computer and digital literacy. The elderly were also provided with personal mentors/coaches who assisted them in using different kinds of digital aids during the online teaching sessions like audio aids, writing and projecting the screen, use of videos and animations, among other things:

So we had some students who were doing their graduation and were interested in training these elderly. We hired them as interns with [GenLink]. ...These students started training the elderly. ..It took almost two to three months to train each elderly teacher. (Founder Director 3, GenLink)

Enhancing ease of technology use related to the measures undertaken to simplify technology use for the elderly. The elderly teachers found it difficult to use the initial portal set up by GenLink through a third party, due to the presence of multiple needless features, difficulties in locating important features, among other things. The founders then internalized technology development and maintenance by recruiting a third co-founder who did the requirement analysis and portal development from scratch. The modified portal had simple and only the most necessary features for delivering online education. Besides this, GenLink also prepared and distributed detailed user manuals to help the elderly in using the portal:

The initial portal was a very heavy software that did not work in the remote rural areas. The user-friendliness of the software was also not that great. ...Also, when they conceptualized, they wanted very complex features in the platform. Most of it never got used. ... So when I designed the platform, I understood the user requirements and made only that. ...We had proper manuals of about $30-40$ pages to standardize the training provided by the interns to the elderly teachers. The manual elaborated everything from how to switch on a computer to how to operate a mouse and our portal. ... We also had a handout that served as a quick guide for the elderly teachers. (Founder Director 3, GenLink). 


\subsection{Towards Creating an Impact on the Two Marginalized Sections}

\subsubsection{Emerging Impacts on the Elderly}

The prolonged engagement of the elderly teachers (more than two years) with the underprivileged children facilitated them to overcome some of the problems they had faced post-retirement. First, their engagement with teaching services for a significant period of time each day, ${ }^{23}$ helped them address their boredom due to lack of productive work. Second, their association with the underprivileged children helped them beat their feelings of social isolation. Third, the thought that they were contributing to the growth of future generations, helped them feel valued and improved their sense of selfworth. Fourth, because they earned a decent income ${ }^{24}$ through their association with GenLink, it augmented their existing income sources and hence improved their financial security. As an illustration, we quote two elderly teachers here:

After both by daughters were married and left home, there was a certain sense of vacuum. ...However, with [GenLink] I literally don't have the time to think about my loneliness. I am busy till even $10 \mathrm{pm}$ in the night. Some of the students are like my own grandchildren.... One kid called me up while I was in the hospital and invited me to a festival in her home. It brought a tear to my eye (Elderly Teacher1, GenLink)

I've always wanted to teach children. [GenLink] is a god given opportunity to solve the little children's problems in rural areas. ... Never thought that the last part of my life would be full of happiness and it's only because of them (the children). (Elderly Teacher2, GenLink)

\subsubsection{Emerging Impacts on the Underprivileged Children}

GenLink' work helped the underprivileged children overcome some of the challenges associated with the rural education system. First, the children got to avoid the underqualified local tuition teachers and got to learn from affectionate and passionate elderly teachers. Besides, learning from an urban teacher also meant a chance to leverage the urban exposure of the teacher and enhance the general knowledge of the students. ${ }^{25}$ Second, the use of multi-media content helped increase the children's' interest in the content taught. Third, field trips

\footnotetext{
${ }^{23}$ The elderly teachers taught between 4 and $6 \mathrm{~h}$ a day.

24 The income came from charging urban students at standard market rates and the rural children at highly subsidized rates.

${ }^{25}$ For instance, teachers who travelled abroad or to other places within the country, showed snow, monuments and new animals to the children during the class.
}

and educational movies made the learning experience more holistic for the children. Fourth, the robust evaluation and monitoring helped the parents obtain a realistic and accurate measure of the progress of their children:

The children really like videos, pictures and movies. Since they are small, they need it (multi-media content) to be attentive. ... The school teachers here simply give the students 8090 (marks) like that. ...[GenLink'] evaluation gives a more correct picture. ...Also, the spoken English abilities of the children have improved a lot. ... They [elderly teachers] teach like they are their friends. (Internet School Owner2, GenLink)

When my children grew up, they listened to bedtime stories from my parents. I firmly believe that it helped build their character. I fear that my grandchildren might miss this. ... [GenLink] provides me with the opportunity to impart my knowledge to the future generations. ...We give a lot of emphasis to the numbers children get in various subjects. I think it's also important to teach them these stories, poems and the morals behind it. (Elderly Teacher2, GenLink)

\section{Discussion}

Markets within developing nations are often characterized by weak institutional environments or environments where the institutions are in conflict with each other (Mair et al. 2012). Such conditions give rise to institutional voids that have to be addressed in order to facilitate developmental goals (Mair et al. 2012; Mair and Marti 2009). Extant research has shown how social enterprises and other developmental agencies navigate through the resource constraints present in such contexts to fill a unitary institutional void. In this context, our study unearths the concept of 'complementary voids' by inquiring into a social enterprise that addresses two voids simultaneously. We define complementary voids as the existence of multiple institutional voids that when tackled simultaneously through innovative institutional works could facilitate the development of synergies and result in the filling of both the voids in the process.

Our conceptualization of complementary voids is grounded in our data that demonstrated how the rural education void and productive ageing void could both be solved by bringing the associated communities together. Specifically, we show how the senior citizens were able to overcome feelings of social isolation and lack of productive opportunities post-retirement through their association with the rural children; while the rural children, in turn, were able to receive an enjoyable and quality educational experience through their association with the elderly teachers. We also show how the elderly's philosophy of 
renunciation and want to contribute to the society helped them develop deeper synergies with the rural children who required education at affordable prices. In this context, we contribute to social entrepreneurship literature and practice (Bhatt et al. 2019) by postulating how complementary voids could be one approach through which entrepreneurs could effectively and parsimoniously address multiple institutional voids. Specifically, we suggest how entrepreneurs situated in resource-constrained environments could leverage complimentary voids to innovatively combine scare resources to help sustain themselves and increase the range of their impact (Domenico et al. 2010; Hota et al. 2019).

Building on our study, we identify the conditions under which complementary voids emerge. Complementary voids require at least two independent but potentially compatible institutional voids. As evidenced through the case of GenLink, the compatibility lies in the potential of the two communities facing the institutional voids to benefit from each other and develop a symbiotic relationship when connected. Such voids may not be easily observed as complementary voids, but may be unravelled by social entrepreneurs who are able to spot the synergies between two seemingly unrelated but compatible institutional voids.

Further, we also demonstrate how the use of ICTs to fill the two complementary voids in our context was met with different challenges in the context of marginalized communities. Specifically, we highlight how the institutional elements and the associated institutional challenges within the context of intervention required efforts much beyond the simple appropriation of technology (Avgerou 2010; Lin et al. 2015; Rhodes 2009) to fill the voids and required institutional work. In this regard, we show how GenLink addressed the institutional challenge of lack of acceptability of online education in the rural context through three types of institutional work. First, legitimizing the new mode of education involved efforts such as engaging local resource people and extending elements present in traditional schools in order to gain the acceptability of the people. Second, educating to enhance awareness concerned the sensitization of the people on the benefits of education in general and the importance of providing good quality education to the children. Third, enriching the learning experience involved efforts to visibly demonstrate the benefits of learning from urban teachers through online education.

We also posit how the elderly's lack of acquaintance with technology further required institutional work by GenLink. First, educating to (re)define norms about technology concerned the need to create awareness about the benefits of technology while simultaneously undermining the negative beliefs associated with it. Second, digital on-boarding of the elderly related to providing digital literacy training and easing their process of technology use. In this context, we contribute to the IS literature on institutional work (Guillemette et al. 2017; Troshani et al. 2018) by surfacing new theoretical dimensions of institutional work based on our research with the marginalized communities.
Specifically, we highlight how the aggregate dimensions and associated second order themes identified in our paper, point to the incremental and gradual nature of ICT centred institutional work in such communities (Marti and Mair 2009).

Moreover, by adopting an institutional work perspective to study an ICT for a development project, we bring to fore a useful but unexplored theoretical lens to understand the challenges associated with implementation of such projects. Specifically, we highlight how an institutional work perspective can help researchers unearth the complex interactions between the technological innovations and the institutional context in which they are deployed (cf Riaz and Qureshi 2017), and thereby help us better understand the actions that intermediaries (the project implementer) should take to ensure successes and avoid failures associated with ICT based development projects. For practice, we suggest that such 'softer' forms of institutional work that involve gradual changes as opposed to aggressive jolts, can help social entrepreneurs gain greater acceptance for their technological projects from such marginalized communities.

Finally, based on our study, we also bring forth two important observations regarding ICT usage in resource constrained contexts. First, while we bring forth the importance of ICT to address complementary voids in the case of GenLink, we emphasize that ICTs may not be the solution to all forms of complementary voids (i.e. when complementary voids exist, ICT is not the only solution, nor is it a prerequisite). For instance, it is possible that a resourceful NGO may be able to address complementary voids without ICT in similar contexts. In GenLink's case however, the physical distance between the marginalized communities ${ }^{26}$ and the organization's resource constraints, ${ }^{27}$ made use of ICT necessary. In fact, the entire initiative by the organization started with an NGO from a rural region approaching the founders asking them to provide a solution to the problem of volunteers not being able to stay for sustained period in the villages and hence students losing out on continuity. ${ }^{28}$

Second, we also note that ICT as an artefact resolving the complementary voids does not exist in a social vacuum (Avgerou 2003, 2010), and exists only in the presence of several supporting social processes (as illustrated in the findings of this paper). ${ }^{29}$ For instance, in the case of GenLink, the organization created a blended learning environment, ${ }^{30}$ wherein additional para teachers were recruited to support the online teachers. Evidently, supporting social processes are also required in addition to ICT to bridge the complementary voids issue.

\footnotetext{
${ }^{26}$ Distance between urban elderly and rural children, coupled with the elderly's restricted mobility due to old age made usage of ICT necessary.

${ }^{27}$ Since GenLink was a start-up, it did not have the resources similar to other large scale NGOs to create a physical environment where different stakeholders can come and interact on a sustained basis.

${ }^{28}$ Refer to the quote and text in page 25 (findings section).

${ }^{29}$ The second order themes 1-5 from Table 1 delineate the supporting processes surrounding ICT that were needed for the system to sustain.

${ }^{30}$ Refer to Table 1 (second order, theme 2 ).
} 
Table 3 Summary of the Data Collected

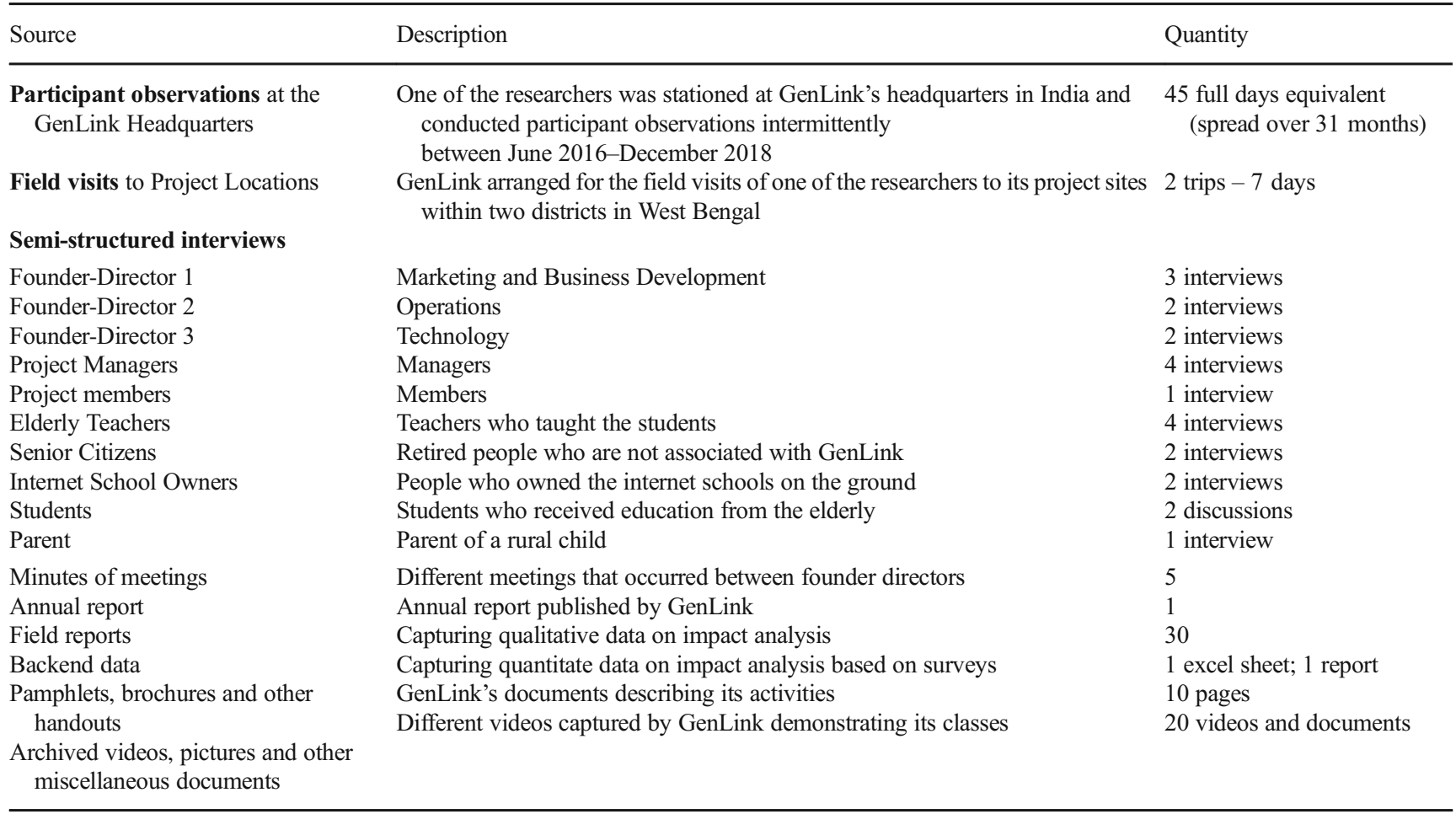

\section{Limitations, Future Research Directions and Conclusion}

This study reports the activities of a social enterprise that leveraged ICTs to bridge the two voids associated with the two marginalized communities in the Indian context. We do not intend to posit that the complementary voids approach is the only way in which social enterprises can address two institutional voids simultaneously. Further, we do not suggest that ICTs are a perquisite to address complementary voids. Our intention is to demonstrate how social enterprises working in resource-constrained environments could go beyond considering multiple voids as having to deal with multiple hurdles and identify complementarities in these voids to increase their impact. Further, we also intend to posit how such complementarities between the voids could improve the effectiveness and efficiencies of the interventions made by social enterprises.

In this context, the choice of research setting and the conditions associated with it could restrict the transferability of the findings. However, our analytical approach of unearthing the complementarities between voids in a developing country context could provide a useful lens for practitioners and scholars working on different developmental projects. For instance, the Grow Movement ${ }^{31}$ provides an interesting opportunity to ground and extend the concept of complementary voids. Grow movement is a case where in managers (working as consultants) from the US who were looking for opportunities

$\overline{31 \text { https://growmovement.org/ }}$ for meaningful work (meaningful work void) were connected to micro-entrepreneurs in Uganda who lacked the education required to develop managerial skills to scale up their small businesses (marketplace education void) using an ICT platform. In this case, the managers used their spare time to deliver a series of free consulting sessions to the micro-entrepreneurs, resulting in the managers feeling valued for their contribution to the society and the micro-entrepreneurs achieving tangible results relating to their business growth (Anderson et al. working paper). We believe that the case of GenLink and Grow Movement would provide pointers to scholars on how the conceptualization of complementary voids could be used as a framework in future research and in turn, enrich the conceptualization using data from their contexts. We also believe that complementary voids approach could be an important managerial strategy for social enterprises working with multiple marginalized communities simultaneously.

While the GenLink and Grow Movement predominantly cover resource constrained environments, we believe that such environments warrant increased attention given the literature states that about 2.7 billion people (conservative estimate) reside in such environments (Dalglish and Tonelli 2016; Kistruck et al. 2013). Despite the nativeness/localness of the conditions presented in our case, we suggest that studies on ICT centred institutional work to address institutional voids in such extreme contexts provides an opportunity to unearth new and interesting insights that are hitherto unexplored in the IS literature. Too many studies on institutional work in general (Mair et al. 2012) and in the IS literature in particular, have focussed on 
large organizations in developed country contexts, thus neglecting the richness and complexity associated with the institutional environments in developing country contexts. Hence, our study is unique in the sense that we explore institutional work by a small social enterprise working in resource constraint context to help marginalized communities in a developing country. Hence, we suggest to our information systems research community working on grand societal challenges (Majchrzak et al. 2016) to leverage institutional work lens (Lawrence et al. 2009) to explore resource constraint contexts which are rarely considered but widely prevalent in the world to provide useful and important theoretical (and practical) contributions.

\section{Appendix}

Table 4 Table showing a representative quote/field note excerpt/ archival data excerpt for each first order code in Table 1

Representative quote/field note excerpt/archival data excerpt $\quad$ Source $\quad$ Corresponding First Order Codes from Table 1

[GenLink] collaborates with various similarly aligned social organizations that GenLink Annual also work towards development of rural or semi-rural communities through Activity education. ...Four NGOs, one social enterprise, one CSC owner and two Report private school headmasters are the enablers who have initiated the sessions (2017-2018) in the study centres which we call [GenLink internet school].

Mobilizing students for the [internet schools] is not an easy task ...We collaborate with educated people in rural areas because people listen to them GenLink) ...Also we can leverage their social networks to mobilize students.

The main reason behind choosing the [para teacher] was the need to [help] these children owing to their fragile age and social conditions. ... The offline coordinators (para teachers) monitor the students in order to make the [children] focus and concentrate.

We have had many instances where the teachers physically visit the internet schools over the weekends to give that physical feel to the children and their parents.

Although our average class size is 15 , sometimes it is a bit more. ... Our [internet schools] have infrastructure like speakers and microphones to help the teachers and students communicate smoothly.

In our [GenLink] platform, the teachers can draw figures, write something and share their screen

The issue of acceptability is addressed by creating an influencer group in and around the [internet schools]. This influencer group is part of the rural community who have the capacity to influence the immediate community, parents and students who would eventually participate in [online education].

I have heard respected elders talk about [online education] as a matter of prestige in our village. ...In my village, [the internet school] serves as a landmark for many people.

We can't put the banner in each and every place without taking the permission. ...We take the permission of the Panchayat leader and then put up these banners in important places

Local branding and consistent visibility in the villages can create some interest amongst rural people... So we used mike sets on vans to talk about [GenLink] across different villages

Whenever [GenLink] manager comes, we call the parents to the school and have meetings with them to discuss the progress of the child

Some parents prefer to wait in the class till the class is over. ...We allow them. ...They also sit with the children during movies

But we found that just promotion is not effective in convincing people to join. We found that setting up a class and showing demo sessions is more effective

Competency based curriculum was provided to the teacher along with relevant videos which were shared with the students. ... Teaching and Learning Materials (TLMs) like - pictures, videos and audios, were provided to students.
GenLink Annual Deployment of Para-teacher

Activity

Report

(2017-2018)

Founder Director Periodic visit of online teachers to the internet 1, GenLink school in person to give feeling of traditional classroom

Founder Director Devices to help teachers hear students and vice 2, GenLink versa, projection of teacher's screen in the

Founder Director internet school

3, GenLink

Founder Director Use local influencers like panchayat head, educated 1 , GenLink people, and respected elders

Internet school owner 2, GenLink

nternet school owner 2, GenLink

Founder Director Awareness creation through advertisement via 1 , GenLink mobile speakers in villages

Internet school owner 2, GenLink

Internet school owner 2,

Founder Director Free demo sessions to attract students 2, GenLink

Parent involvement in the classes through in class visits, parent teaching meeting

Screening of educational movies and arranging educational trips to engage parents and students

GenLink Annual Multi-media content to make learning interesting Activity Report

(2017-2018))

Founder Director Inclusion of poems, storytelling by the elderly 2, GenLink teachers 
Table 4 (continued)

Representative quote/field note excerpt/archival data excerpt

Source

Corresponding First Order Codes from Table 1

Since the elderly have a life time of experiences, we had separate sessions to make them tell stories and other things. ...story of Ramanyan, Mahabharata, different cultural stuff, fairy tales, etc.

We give two types of counselling ...career counselling and psychological counselling. In career counselling we give exposure on where and what to study depending on needs and preferences. ...In psychological counselling our mentors help students facing different problems

Some students may not be able to cope up with some subjects or may need revision classes before exams. Our teachers provide doubt clearing sessions throughout the week

Over the period of six months about three assessments were conducted (both oral and written), which showed that the children not only learned well, but also enjoyed what was taught

We collect data through the teacher app, internet school owner app and the portal ...Using the teacher app, we track the class performance and exam scores of each child ... In the coordinator app we track the student attendance and teacher performance. ...We also use the data from the portal to check login time and the smoothness of the classes.

Founder Director Personal counselling for students on a periodic basis 1 , GenLink

Founder Director Personal post class sessions for doubt clarification 1 , GenLink

GenLink Annual Enactment of robust online evaluation system Activity

Report

(2017-2018)

Founder Director Analytics system to track progress of each child 3, GenLink

Table 5 Table showing a representative quote/field note excerpt/ archival data excerpt for each first order code in Table 2

Representative quote/field note excerpt/ archival data excerpt $\quad$ Source $\quad$ Corresponding First Order Codes from Table 2

The basic idea is to demonstrate the power of social media to the elderly. It Authors' note based involves explaining the critical role that elderly can play to create an inclusive world wherein they connect with the young minds from underprivileged communities through social media. In doing so, they can enhance the quality of education and the well-being of students in remote rural areas.

Many elderly people go to places to visit their children or need health breaks. ... So they understand that with our platform they can withdraw from working and come back again

I think because they see different things in the news and because they have never used computers, some elderly were scared....We sat with them for many days to help them.

There was one elderly whose name was professor [elderly teacher]. ... She had [health ailment] and she was unable to move from her place and her hands used to shiver all the time. ... Training [elderly teacher] was tough initially because of the mental blockage she had ... later she absolutely subscribed to this notion of engaging herself and making herself productive

The elderly were provided training and handholding on the effective use of computers to perform tasks like imparting e-tutoring, e-learning, video-chatting, e-mailing, social networking, among other things

I used to visit each of the elderly places along with the interns and then sit with them and explain them and I used to show them videos

At that point of time we didn't have [the current] platform, we had [older version] and [older version] was pretty difficult for anyone. ..It was difficult even for us. [Elderly] used to struggle a lot to understand [older version], [Current version] is much easier it is absolutely user friendly

When we started off there was no such manual for the elderly. ...We created it from scratch to cater to their needs on archival

documents

Founder Director 2, Explaining how technology would provide GenLink

Founder Director 1 , GenLink

Founder Director 2, GenLink

Sensitizing on how technology can help share their knowledge to the larger mass

flexibility in workplace, working hours and work schedules

Addressing fear of technology through handholding

Addressing mental blockage regarding technology use by showing role models through videos

Periodic group training sessions for the elderly teachers

on archival documents

Founder Director 2, Offline and online personal coaching to use audio GenLink aids, projecting screen while teaching online

Founder Director 2, Enhancing the user friendliness of the GenLink GenLink interface

Founder Director 3, Providing detailed manuals and videos to simplify GenLink usage of the portal 


\section{References}

Afridi, F. (2011). The impact of school meals on school participation: Evidence from rural India. Journal of Development Studies, 47(11), 1636-1656.

Agrawal, T. (2014). Educational inequality in rural and urban India. International Journal of Educational Development, 34(1), 11-19.

Amaeshi, K., Adegbite, E., \& Rajwani, T. (2016). Corporate social responsibility in challenging and non-enabling institutional contexts: Do institutional voids matter? Journal of Business Ethics, 134(1), 135-153.

Anderson, S. J., Chintagunta, P. K., \& Vilcassim, N. (working paper Unpublished). Stimulating marketing strategy innovation with entrepreneurs in Uganda: Examining the impact of Skype-aided business coaching on firm sales. Working Paper (unpublished).

Ashraf, M., Hanisch, J., \& Swatman, P. (2009). ICT intervention in the "Chandanbari" village of Bangladesh: Results from a field study. Information Systems Frontiers, 11(2), 155-166.

Avgerou, C. (2003). The Link between ICT and Economic Growth in the Discourse of Development. In Organizational information systems in the context of globalization (Vol. 126, pp. 373-386). Springer US.

Avgerou, C. (2010). Discourses on ICT and development. Information Technologies \& International Development, 6(3), 1-18.

Bandyopadhyay, S., Dey, P., Bardhan, A., Banerjee, S., \& Das, S. (2015). OwlishOracle : Architecting a social media-based e-learning platform for primary education of underprivileged children by senior citizens of India. International Journal of Social Media and Interactive Learning Environments, 3(4), 322-339.

Banerjee, S. B., \& Jackson, L. (2017). Microfinance and the business of poverty reduction: Critical perspectives from rural Bangladesh. Human Relations, 70(1), 63-91.

Bhatt, B., Qureshi, I., \& Riaz, S. (2019). Social entrepreneurship in nonmunificent institutional environments and implications for institutional work: Insights from China. Journal of Business Ethics, 1-26.

Binz, C., Kiparsky, M., Harris-Lovett, S., Truffer, B., \& Sedlak, D. L. (2015). The thorny road to technology legitimation - Institutional work for potable water reuse in California. Technological Forecasting and Social Change, 103, 249-263.

Borooah, V. K., \& Iyer, S. (2005). Vidya, Veda, and Varna: The influence of religion and caste on education in rural India. Journal of Development Studies, 41(8), 1369-1404.

Brooks, L., \& Alam, M. S. (2013). Designing an information system for updating land records in Bangladesh: Action design ethnographic research (ADER). IFIP Advances in Information and Communication Technology, 402, 359-374.

Chemin, M. (2008). The benefits and costs of microfinance: Evidence from Bangladesh. Journal of Development Studies, 44(4), 463-484.

Choudhury, A. (2006). Revisiting dropouts: Old issues, fresh perspectives. Economic and Political Weekly, 41(51), 5257-5263.

Cruz-Jesus, F., Oliveira, T., Bacao, F., \& Irani, Z. (2017). Assessing the pattern between economic and digital development of countries. Information Systems Frontiers, 19(4), 835-854

Cui, M., Pan, S. L., Newell, S., \& Cui, L. (2017). Strategy, resource orchestration and E-commerce enabled social innovation in rural China. Journal of Strategic Information Systems, 26(1), 3-21.

Dalglish, C., \& Tonelli, M. (2016). Entrepreneurship at the Bottom of the Pyramid. New York: Routledge.

Deng, X., Joshi, K., \& Galliers, R. D. (2016). The duality of empowerment and marginalization in microtask crowdsourcing: Giving voice to the less powerful through value sensitive design. MIS Quarterly, 40(2), 279-302.
Dionigi, R. A. (2015). Stereotypes of aging: Their effects on the health of older adults. Journal of Geriatrics, 2015, 1-9.

Di Domenico, M., Haugh, H., \& Tracey, P. (2010). Social bricolage: Theorizing social value creation in social enterprises. Entrepreneurship: Theory and Practice, 34(4), 681-703.

Dorado, S., \& Ventresca, M. J. (2013). Crescive entrepreneurship in complex social problems: Institutional conditions for entrepreneurial engagement. Journal of Business Venturing, 28(1), 69-82.

Dreze, J., \& Kingdon, G. (2001). School participation in rural Indiareview of development economics, Review of Development Economics., 5(1), 1-24.

Eisenhardt, K. M. (1989). Building theories from case study research. Academy of Management Review, 14(4), 532-550.

Ganju, K. K., Pavlou, P. A., \& Banker, R. D. (2016). Does information and communication technology Lead to the well-being of nations? A country-level empirical investigation. MIS Quarterly, 40(2), 417430.

Gioia, D. A., Corley, K. G., \& Hamilton, A. L. (2013). Seeking qualitative rigor in inductive research: Notes on the Gioia methodology. Organizational Research Methods, 16(1), 15-31.

Gleason, H., \& Butler, R. (1985). Productive aging: Enhancing vitality in later life. Springer Publishing Company.

Gokhale, S. D. (1998). Community experiences in active ageing: An NGO perspective. Ageing International, 24(2-3), 154-162.

Gregor, S., Imran, A., \& Turner, T. (2013). A "sweet spot" change strategy for a least developed country: Leveraging e-government in Bangladesh. European Journal of Information Systems, 23(6), 1-17.

Guillemette, M. G., Mignerat, M., \& Paré, G. (2017). The role of institutional work in the transformation of the IT function: A longitudinal case study in the healthcare sector. Information and Management, 54(3), 349-363.

Haihambo, C. K. (2020). Inclusive Approaches to School Counseling: Arguing for Culturally-Responsive Psycho-Social Support for Learners From Indigenous Communities. In Addressing Multicultural Needs in School Guidance and Counseling (pp. 119). IGI Global.

Hamann, R., \& Bertels, S. (2018). The institutional work of exploitation: Employers' work to create and perpetuate inequality. Journal of Management Studies, 55(3), 394-423.

Henriksen, H. Z., Laumer, S., Bunker, D., Wastell, D., Elbanna, A., Srivastava, S. C., et al. (2014). Research on information systems failures and successes: Status update and future directions. Information Systems Frontiers, 17(1), 143-157.

Hinings, B., Gegenhuber, T., \& Greenwood, R. (2018). Digital innovation and transformation: An institutional perspective. Information and Organization, 28(1), 52-61.

Hota, P. K., Mitra, S., \& Qureshi, I. (2019). Adopting Bricolage to overcome resource constraints: The case of social Enterprises in Rural India. Management and Organization Review, 15(2), 371-402.

Ingle, G. K., \& Nath, A. (2008). Geriatric health in India: Concerns and solutions. Indian Journal of Community Medicine, 33(4), 214-218.

ITU. (2011). The role of ICT in advancing growth in least developed countries: Trends, challenges and opportunities. Geneva.

Jeste, D. V., \& Vahia, I. V. (2008). Comparison of the conceptualization of wisdom in ancient Indian literature with modern views. Psychiatry, 71(3), 197-209.

Jha, S. K., Pinsonneault, A., \& Dube, L. (2016). The evolution of an ICT platform-enabled ecosystem for poverty alleviation: The case of Ekutir. MIS Quarterly, 40(2), 1-16.

Kainth, G. S. (2006). A Mission approach to Sarva Shiksha Abhiyan. Economic and Political Weekly, 41(30), 3288-3291. 
Kistruck, G. M., Beamish, P. W., Qureshi, I., \& Sutter, C. J. (2013). Social intermediation in base-of-the-pyramid markets. Journal of Management Studies, 50(1), 31-66.

Kostova, T., Roth, K., \& Dacin, M. T. (2008). Institutional theory in the study of multinational corporations: A critique and new directions. Source: The Academy of Management Review Academy of Management Review, 33(4), 994-1006.

Lawrence, T. B., Hardy, C., \& Phillips, N. (2002). Institutional effects of Interorganizational collaboration : The emergence of proto- institutions. Academy of Management Journal, 44(1), 281-290.

Lawrence, T. B., Leca, B., \& Zilber, T. B. (2013). Institutional work: Current research, new directions and overlooked issues. Organization Studies, 34(8), 1023-1033.

Lawrence, T. B., \& Suddaby, R. (2006). Institutions and institutional work. The SAGE handbook of organization studies (2nd ed.).

Lawrence, T. B., Suddaby, R., \& Leca, B. (2009). Introduction: Theorizing and studying institutional work. In Institutional Work: Actors and Agency in the stduies of organizations. New York: Cambridge University Press.

Lawrence, T., Suddaby, R., \& Leca, B. (2011). Institutional work: Refocusing institutional studies of organization. Journal of Management Inquiry, 20(1), 52-58.

Leach, F., \& Sitaram, S. (2007). Sexual harassment and abuse of adolescent schoolgirls in South India. Education, Citizenship and Social Justice, 2(3), 257-277.

Leong, C., Pan, S. L., \& Newell, S. (2016). The emergence of self organizing E-commerce ecosystems in remote villages of China: A tale of digital empowerment for rural development. MIS Quarterly, 40(2), 475-484.

Lin, C. I. C., Kuo, F.-Y., \& Myers, M. D. (2015). Extending ICT4D studies: The value of critical research. MIS Quarterly, 36(3), 697712

Mair, J., \& Marti, I. (2009). Entrepreneurship in and around institutional voids: A case study from Bangladesh. Journal of Business Venturing, 24(5), 419-435.

Mair, J., Marti, I., \& Ventresca, M. J. (2012). Building inclusive Markets in Rural Bangladesh : How intermediaries work institutional voids. Academy of Management Journal, 55(4), 819-850.

Mair, J., \& Reischauer, G. (2017). Capturing the dynamics of the sharing economy: Institutional research on the plural forms and practices of sharing economy organizations. Technological Forecasting and Social Change, 125(2017), 11-20.

Majchrzak, A., Markus, M. L., \& Wareham, J. (2016). Designing for digital transformation: Lessons for information systems research from the study of ICT and societal challenges. MIS Quarterly, 40(2), 267-277.

Mansell, R. (2010). Power and interests in developing knowledge societies : Exogenous and endogenous discourses in contention. Germany.

Marti, I., \& Mair, J. (2009). Bringing change into the lives of the poor: Entrepreneurship outside traditional boundaries. In Thomas B. Lawrence \& R. Suddaby (Eds.), Intitutional work: Actors and Agency in the Instituional studies of Oragnziations. New York: Cambridge University Press.

Maurer, C. C., Qureshi, I. (2019). Not just good for her: A temporal analysis of the dynamic relationship between representation of women and collective employee turnover. Organization Studies. https://doi.org/10.1177/0170840619875480.

McGrath, K. (2016). Identity verification and societal challenges: Explaining the gap between service provision and development outcomes. MIS Quarterly, 40(2), 485-500.
Mertha, A. (2009). Fragmented authoritarianism 2.0: Political pluralization in the chinese policy process. China Quarterly, 200(200), 995 1012.

Morato, J., Ruiz-Robles, A., Sanchez-Cuadrado, S., \& Marzal, M. A. (2016). Technologies for digital inclusion: Good practices dealing with diversity. In Wealth Creation and Poverty Reduction: Breakthroughs in Research and Practice (pp. 17-37). IGI Global.

Osland, J. S., \& Bird, A. (2000). Beyond sophisticated stereotyping: Cultural sensemaking in context. Academy of Management Perspectives, 14(1), 65-77.

$\mathrm{Pal}, \mathrm{J}$. (2009). If the state provided free computer literacy, would it find takers? Evidence and propositions from the Akshaya project in India. Information Systems Frontiers, 11(2), 105-116.

Pal, J., Lakshmanan, M., \& Toyama, K. (2009). "My child will be respected": Parental perspectives on computers and education in rural India. Information Systems Frontiers, 11(2), 129-144.

Palepu, K. G., \& Khanna, T. (1998). Institutional voids and policy challenges in emerging markets the recent economic turmoil in Asian such as those of Thai. Brown Journal of World Affairs, 5(1), 71-78.

Prakash, A., \& De, R. (2015). Importance of development context in ICT4D projects: A study of computerization of land records in India. Information Technology \& People, 28(1), 2-33.

Qureshi, I., Kistruck, G. M., \& Bhatt, B. (2016). The enabling and constraining effects of social ties in the process of institutional entrepreneurship. Organization Studies, 37(3), 425-447.

Qureshi, I., Sutter, C., \& Bhatt, B. (2018). The transformative power of knowledge sharing in settings of poverty and social inequality. Organization Studies, 39(11), 1575-1599.

Rahman, M., Bose, S., Babu, M. M., \& Dey, B. L. (2019). Value cocreation as a dialectical process : Study in Bangladesh and Indian Province of West Bengal. Information Systems Frontiers, 1-19.

Ravishankar, M. N. (2013). Public ICT innovations: A strategic ambiguity perspective. Journal of Information Technology, 28(4), 316-332.

Rhodes, J. (2009). Using Actor-Network Theory to Trace an ICT ( Telecenter ) Implementation Trajectory in an African Women' Micro-Enterprise Development Organization, 5(3), 1-20.

Riaz, S., \& Qureshi, I. (2017). Emergence of a new institutional logic: Shaping the institutionally complex field of community radio in India. In Emergence, 50, 383-418.

Sahay, S., \& Walsham, G. (2017). Information technology, innovation and human development: Hospital information Systems in an Indian State. Journal of Human Development and Capabilities, 18(2), 275-292.

Sharma, P. K. (2018). Rural Development Scenario and Strategies in Bundelkhand Region of Madhya Pradesh, India. American Journal of Rural Development, 6(3), 104-108.

Siddhu, G. (2011). Who makes it to secondary school? Determinants of transition to secondary schools in rural India. International Journal of Educational Development, 31(4), 394-401.

Stenholm, P., Acs, Z. J., \& Wuebker, R. (2013). Exploring country-level institutional arrangements on the rate and type of entrepreneurial activity. Journal of Business Venturing, 28(1), 176-193.

Stephan, U., Uhlaner, L. M., \& Stride, C. (2015). Institutions and social entrepreneurship: The role of institutional voids, institutional support, and institutional configurations. Journal of International Business Studies, 46(3), 308-331.

Tarafdar, M., Singh, R., \& Anekal, P. (2012). Market development at the bottom of the pyramid: Examining the role of information and communication technologies. Information Technology for Development, 18(4), 311-331.

Tiwari, S., \& Pandey, N. (2013). The Indian concepts of lifestyle and mental health in old age. Indian Journal of Psychiatry, 55(6), 288. 
Tracey, P., \& Phillips, N. (2011). Entrepreneurship in emerging markets strategies for new venture creation in uncertain institutional contexts. Management International Review, 51(1), 23-39.

Troshani, I., Janssen, M., Lymer, A., \& Parker, L. D. (2018). Digital transformation of business-to-government reporting: An institutional work perspective. International Journal of Accounting Information Systems, 31(March), 17-36.

Venkataraman, H., Vermeulen, P., Raaijmakers, A., \& Mair, J. (2016). Market meets community: Institutional logics as strategic resources for development work. Organization Studies, 37(5), 709-733.

Venkatesh, V., Bala, H., \& Sambamurthy, V. (2016). Implementation of an information and communication Technology in a Developing. Information Systems Research, 27(3), 558-579.

Wadhwani, R. D. (2018). Poverty's monument: Social problems and organizational field emergence in historical perspective. Journal of Management Studies, 55(3), 545-577.

Walsham, G. (2012). Are we making a better world with ICTs? Reflections on a future agenda for the IS field. Journal of Information Technology, 27(2), 87-93.

Wang, P., \& Swanson, E. B. (2007). Launching professional services automation: Institutional entrepreneurship for information technology innovations. Information and Organization, 17(2), 59-88.

Webb, J. W., Tihanyi, L., Ireland, R. D., \& Sirmon, D. G. (2009). You say illegal, I say legitimate: Entrepreneurship in the informal economy. Academy of Management Review, 34(3), 492-510.

Yin, R. (2003). Case study research: Design and methods, thousand oaks, 3 (3rd ed.). Thousand Oaks.

Young, A. G. (2018). Using ICT for social good: Cultural identity restoration through emancipatory pedagogy. Information Systems Journal, 28(2), 340-358.

Zietsma, C., \& Lawrence, T. B. (2010). Institutional work in the transformation of an organizational field: The interplay of boundary work and practice work. Administrative Science Quarterly, 55(2), 189221.

Publisher's Note Springer Nature remains neutral with regard to jurisdictional claims in published maps and institutional affiliations.

Rishikesan Parthiban is a Doctoral candidate of Management Information Systems Group at the Indian Institute of Management, Calcutta, India. He is pursuing his dissertation on the topic "Essays on Digital Social Innovations for Rural Development". His work has been recognized through seven national and international awards that he received during his doctoral period. Rishikesan holds a B.E (Hons.) degree in Electrical and Electronics Engineering from the Birla Institute of Technology and Science, Pilani, India and has two years of industry experience in the VLSI Chip Design sector.

Israr Qureshi is a Professor of Social Entrepreneurship and ICT for Development at the ANU College of Business and Economics. He is currently involved in multiple research projects that investigate various aspects of social value creation through social entrepreneurship and Information and Communication Technology for Sustainable Development (ICTSD). His research has been published in MIS Quarterly, Journal of Management Studies, Journal of Management, Organizational Research Methods, Organization Studies, Journal of Organization Behavior, among others.

Somprakash Bandyopadhyay is a Professor in Management Information Systems Group, Indian Institute of Management, Calcutta and Founder-Director of Social Informatics Research Group, a multidisciplinary research group at IIM Calcutta. He is also the FounderMentor of a social business venture working towards social inclusion through digital inclusion. Somprakash, a $\mathrm{PhD}$ in Computer Science, has around 40 years of experience in teaching, research and system development in several organizations of international repute. He was a fellow of the Alexander von Humboldt Foundation, Germany and fellow of the Japan Trust International Foundation.

Babita Bhatt is a Lecturer at Research School of Management, Australian National University. Her research interest lies at the intersection of community, civil society and organizations. She applies social capital theory and capability approach to understand how social impact is achieved by organizations engaged in poor communities. Her work has been published in Organization Studies and the Journal of Business Ethics. She has received funding from various research agencies in Australia, Canada, Hong Kong and India.

Saravana Jaikumar is an Assistant Professor in the Marketing Group at the Indian Institute of Management, Calcutta, India. His research work has been published in International journals of repute including Journal of Advertising Research, Journal of Business Research, Marketing Letters and Journal of Product and Brand Management. He is working on several development related studies including, examining the effects of pharmaceutical price regulation in India, examining the effects of marketplace literacy programs, and health-beliefs and health issues among the disadvantaged in India. 